\title{
Práticas informacionais dos visitantes do Museu Itinerante Ponto UFMG
}

\author{
Tatiane Krempser Gandra \\ Doutoranda; Universidade Federal de Minas Gerais (UFMG), Belo Horizonte, MG, Brasil; \\ tatikempser@gmail.com \\ Carlos Alberto Ávila Araújo \\ Pós-doutor; Universidade Federal de Minas Gerais (UFMG), Belo Horizonte, MG, Brasil; \\ casalavila@yahoo.com.br
}

\begin{abstract}
Resumo: Este estudo explora um ponto de interlocução entre estudos de usuários da informação e estudos de visitante da Museologia e investiga a interação dos visitantes do Museu Itinerante Ponto UFMG com a informação. A pesquisa embasa-se no conceito de práticas informacionais enquanto um fazer etnográfico, recorrendo à observação e entrevista para coleta de dados. Os resultados apontam que inúmeros fatores influenciam a interação entre o sujeito e os elementos do museu. Muitas vezes, os relatos dos entrevistados contradizem as observações, e a explicação para tal contradição está num misto de fatores, perpassando pela concepção dos sujeitos sobre museus e o nível de preocupação deles quanto à imagem que querem transmitir de si. Concluímos que a observação participante, aliada à entrevista, mostrou-se apropriada para desvelar os significados da experiência de visita, possibilitando-nos captar não apenas o que os visitantes dizem que fazem, mas também o que eles realmente fazem e o que pensam sobre o que fazem.
\end{abstract}

Palavras-chave: Práticas informacionais. Estudos de usuários. Estudos de visitante. Museus. Etnografia.

\section{Introdução}

A relação de visitantes com museus tem sido investigada de diferentes maneiras desde o início do século XX. Tal relação se dá desde a observação do percurso físico do visitante pela exposição, dos estudos com ênfase nas dimensões psicológica, de aprendizagem, emocionais ou cognitivas até os estudos mais recentes, que enfocam a dimensão contextual e comunicacional da experiência de visita. 
Buscamos, neste artigo, explorar um ponto de interlocução entre os estudos de usuários da informação da Ciência da Informação (CI) e os estudos de visitante da Museologia, a partir da apropriação do conceito de práticas informacionais, para a compreensão da experiência dos visitantes do Museu Itinerante Ponto UFMG. Problematizamos a relação entre o sujeito e a sua experiência de visitar museus, sob a ótica da dimensão informacional, com intuito de compreender como ocorre a interação do visitante com a informação. Esse diálogo entre os estudos de visitantes e os usuários da informação é favorecido, dentre outros, por dois movimentos: a reconfiguração, pela qual passa a Museologia, a partir de suas abordagens contemporâneas e a perspectiva sociocultural da CI e dos estudos de usuários da informação (ARAÚJO, 2013).

A Museologia vivencia, a partir das décadas finais do século XX, uma série de movimentos teóricos e práticos que constituem as abordagens contemporâneas, as quais buscam adotar uma nova postura; questionando a função social do museu, que passa a ser compreendido como um meio de transformação social. Sob esta perspectiva, além da função de preservar, o museu deve integrar a comunidade às suas ações. Desta forma, o visitante é percebido como protagonista, assumindo uma postura ativa frente aos fenômenos museais (PÉREZ SANTOS, 2000; ALONSO FERNÁNDEZ, 2012).

Já a perspectiva sociocultural dos estudos de usuários, buscando superar uma visão mais mecanicista e isolacionista das abordagens anteriores, percebe a relação dos sujeitos com a realidade social, incluindo a informação como um processo dialético e de construção mútua e constante de significados sobre tudo o que os cerca. Assim, tem-se a noção de informação, bem como os critérios de necessidade, relevância e valor da informação, enquanto construções intersubjetivas. A partir dessa perspectiva, os sujeitos e as suas ações só podem ser compreendidos dentro de um específico contexto histórico, político, econômico e sociocultural que constituem os fenômenos informacionais. É o que pretende o conceito de práticas informacionais - noção partilhada por estudos realizados conforme a abordagem sociocultural dos estudos de usuários, e que é discutida de modo mais detalhado neste artigo. 


\section{Diálogo entre os estudos de visitante e de usuários da informação}

Apresentamos uma breve explanação histórica dos estudos de visitante e dos estudos de usuários da informação e, em seguida, discorremos sobre a articulação de tais campos, a partir do conceito de práticas informacionais.

\subsection{Os estudos de visitante na Museologia}

Os estudos de visitante, cuja origem ocorre no início do século $\mathrm{XX}$, nascem como investigações para avaliar diferentes tipos de museus e exposições, sendo utilizadas como instrumentos para auxiliar a gestão dos museus e a tomada de decisões. Essa preocupação com o público deve-se aos questionamentos pelos quais os museus passam ao longo do século XIX. Neste momento, os museus buscam adaptar-se aos novos tempos e começam a preocupar-se mais com seus visitantes (HOPPER-GREENHILL, 1998).

Até a década de 1920, os estudos dedicavam-se à observação do comportamento do visitante. As investigações de B. Gilman sobre a 'fadiga no museu' exemplificam tal fato. Além disso, Robinson, em 1928, investigou quatro aspectos do comportamento dos visitantes: duração da visita, número de salas visitadas, número de obras visitadas em casa sala e tempo de parada em cada obra. Na década de 1930, são realizadas inúmeras investigações sobre o perfil dos visitantes, incluindo aspectos como ocupação, lugar de residência, motivo da visita, grau de satisfação e etc. Uma importante mudança acontece pouco antes da Segunda Guerra Mundial: o foco dos estudos se desloca do comportamento do público para a análise da exposição e de seu impacto sobre o visitante.

Nas décadas de 1960 e 1970, destacam-se os estudos de Shettel e Screven, que se interessam pela transmissão das mensagens e buscam verificar se os objetivos de aprendizagem e pedagógicos pretendidos pelos museus foram alcançados, incluindo, nos estudos, aspectos cognitivos e afetivos. (PÉREZ SANTOS, 2000). É neste momento que começam a surgir críticas aos estudos realizados até o momento, em relação à falta de metodologias adequadas. 
Estudos desenvolvidos conforme perspectivas cognitivistas começam a ser desenvolvidos nas décadas de 1970 e 1980. Araújo (2013) destaca os autores Eason, Friedman, Borun, Card, Moran e Newell, que investigaram a experiência de visitação dos museus a partir de conceitos de memória, aprendizagem e percepção, e McManus, com a Teoria dos filtros, investiga os fatores sociais relacionados à visita, a partir de uma base construtivista.

A partir da década de 1990, surgem investigações orientadas por outras perspectivas, além do enfoque comportamental ou da influência da psicologia. Podem ser apontados como exemplos as investigações dos seguintes autores: Hooper-Greenhill (1998) que foca a dimensão comunicacional da experiência museal; o modelo de Uzzel que, orientado por perspectiva sociocognitiva, visa verificar a influência das interações sociais na visita ao museu; e o modelo de experiência museal interativa de Falk e Dierking (PÉREZ SANTOS, 2000).

Esse modelo de experiência museal interativa pode ser considerado um importante avanço para os estudos de visitante, pois busca entender a experiência de visita ao museu de modo holístico, considerando dimensões não consideradas pelos estudos anteriores. Para Falk e Dierking (2011), a experiência museal só pode ser compreendida se consideramos os contextos pessoal, físico e sociocultural. O contexto pessoal refere-se às expectativas, interesses e experiências prévias do visitante, bem como sua própria concepção sobre o que é um museu, dentro da sociedade e cultura nas quais ele está inserido. O contexto físico abarca o edifício onde o museu está sediado, todos os objetos e artefatos, e todo o ambiente no qual ocorre a interação entre visitante e museu. Este modelo também considera o contexto sociocultural, tanto do visitante quanto do museu, pois considera que ambos estão inseridos em uma cultura específica, com suas crenças e valores, o que influencia as decisões e os comportamentos dos visitantes. A ênfase deste modelo de experiência museal interativa está no aspecto educacional de visita. A proposta do modelo é investigar como estes contextos podem favorecer uma boa experiência de aprendizagem no museu.

Como pode ser percebido nesta breve explanação, existem variadas formas de se estudar a experiência de visitação ao museu. Se pensarmos na 
evolução histórica dos estudos de visitantes, tendo como ponto de partida seus paradigmas de referência, percebemos que os primeiros estudos de visitante (e parte dos estudos desenvolvidos atualmente) foram concebidos como ferramentas de avaliação de exposições, servindo como instrumentos de gestão e tomada de decisão, o que revela o viés funcionalista destas investigações. Já a perspectiva cognitivista, para Pérez Santos (2000) e Köptcke (2003), começa a ser utilizada por pesquisadores a partir da década de 1970. Os estudos mais recentes, por sua vez, têm se apoiado em perspectivas sociocognitivas ou socioculturais.

Podemos observar uma semelhança com a evolução histórica dos estudos de usuários da informação, que possui duas abordagens já consolidadas: a abordagem tradicional, de cunho funcionalista; e a abordagem alternativa ou cognitiva, cuja base está no behaviorismo. Além destas, há uma terceira abordagem, a sociocultural, ainda em fase de consolidação, que prioriza o contexto sociocultural e a historicidade dos sujeitos. Acreditamos que essa abordagem sociocultural tem muito a contribuir para com o campo de estudos de visitantes de museus, especialmente, pela base teórica oriunda do conceito de práticas informacionais, como discutido a seguir.

\subsection{Os estudos de usuários da informação}

Os estudos de usuários surgem nas primeiras décadas do século $\mathrm{XX}$ com os estudos de comunidade, que se preocupavam com os hábitos de leitura dos usuários de bibliotecas. Esses primeiros estudos desenvolvidos, até os do início da década de 1970, podem ser caracterizados como estudos de uso da informação, por se preocuparem com o acesso físico aos itens. Em geral, são investigações quantitativas e de caráter puramente empírico, que buscam estatísticas a fim de medir o comportamento dos usuários (FIGUEIREDO, 1994).

Esses estudos são considerados pertencentes à abordagem tradicional ou física dos estudos de usuários. Uma característica marcante é a noção de utilidade, um aspecto visível do positivismo e, especialmente, do funcionalismo. Os estudos eram realizados com o intuito de aperfeiçoar serviços, sistemas e 
fluxos de informação. Outro aspecto importante é a noção de informação, entendida como um ente objetivo cujo significado é fixo, neutro e que independe da interpretação e dos estados mentais dos sujeitos. Esta abordagem desconsidera que a informação, os sistemas e os usuários estão inseridos em um contexto sociocultural (GONZÁLEZ TERUEL, 2005; ARAÚJO, 2010).

As investigações dessa primeira abordagem sofrem críticas em relação à ausência de uma base teórica e metodológica no desenvolvimento dos estudos. E é a partir da tentativa de pesquisadores em responder a tais críticas que acontece um grande salto conceitual, com a abordagem alternativa ou cognitiva, com o desenvolvimento de vários modelos e teorias. Os estudos buscam entender as necessidades de informação dos sujeitos, a partir de suas perspectivas individuais, contextualizando a situação real que desencadeou a necessidade de informação (CHOO, 2003; GONZÁLEZ TERUEL, 2005).

Um pressuposto fundamental dessa abordagem passa pela noção de necessidade de informação e a dimensão cognitiva: assume-se que os sujeitos possuem necessidades de informação ou lacunas na mente, que seriam preenchidas por determinada informação. Vários modelos são desenvolvidos no intuito de investigar as etapas pelos quais os usuários passam nos processos de busca e até uso da informação (como os de Tom Wilson, Brenda Dervin; Carol Kuhlthau; Taylor; Belkin, Oddy e Brooks; Ellis). As pesquisas passam considerar fatores como as características cognitivas, emocionais, fisiológicas e situacionais que permeiam a interação do usuário com a informação.

Wilson (1981) cunha o termo comportamento informacional para os estudos dessa abordagem, definindo-o como a totalidade do comportamento humano frente às fontes e canais de informação, incluindo a busca ativa e passiva de informação e o seu uso. Adota-se uma visão específica sobre informação enquanto uma construção subjetiva na mente do sujeito, e sobre o modo como as pessoas conhecem a realidade. Desse modo, cada pessoa possuiria uma determinada estrutura de conhecimentos prévios, e ao se adicionar uma nova informação, o resultado seria uma nova estrutura de conhecimentos, numa lógica de acumulação. Assim, a informação é percebida como algo capaz de reduzir incertezas e solucionar dúvidas ou problemas. 
A dimensão situacional é considerada como um fator interveniente, voltando-se, principalmente, para o contexto mais individual, especialmente os contextos de tarefa e trabalho, sendo algo que pode favorecer ou dificultar o processo de busca e uso da informação por parte do usuário. E a dimensão emocional também é vista como uma interferência, muitas vezes percebida como um problema.

Embora os modelos desta abordagem assumam-se como influenciados por abordagens compreensivas, em especial o construtivismo, eles sofrem críticas por não prestarem a devida importância a uma série de outras dimensões que influenciam as ações e opiniões dos usuários em sua interação com a informação, como as dimensões econômicas, políticas e socioculturais, bem como a historicidade dos sujeitos (GONZÁLEZ TERUEL, 2005).

Motivados por essas críticas, pesquisadores do campo propõem-se a buscar novas direções, reconstruindo conceitos e dimensões presentes nos estudos, a partir de um novo modo de se olhar para os fenômenos investigados. Deste esforço, surge a abordagem sociocultural, cuja principal característica é a relevância dada ao contexto do usuário nos estudos, que passam a considerar a influência dos precedentes históricos e das dimensões sociocultural, econômica e política na interação dos sujeitos com a informação. É o entendimento de que, além de sua dimensão objetiva, algo só se torna informação e ganha significado para os sujeitos a partir do contexto no qual a informação e o sujeito estão inseridos (GONZÁLEZ TERUEL, 2005; ARAÚJO, 2013).

Essa é uma diferença essencial entre a abordagem social e a cognitiva. Se antes o contexto é assumido como um fator interveniente - elementos que poderiam favorecer ou dificultar os processos de busca e uso da informação; nessa abordagem ele é considerado um fator constituinte, ou seja, o contexto em que o sujeito viveu toda a sua vida, os grupos sociais aos quais pertence, os papéis que assume diariamente, bem como a sua historicidade, são considerados aspectos que o formam, que constituem as suas ações e opiniões, inclusive no que tange sua interação com a informação. 


\subsection{O conceito de práticas informacionais e suas contribuições para os estudos de visitante}

As pesquisas realizadas conforme os pressupostos da abordagem social têm sido denominadas estudos das práticas informacionais, em oposição aos estudos de comportamento informacional (SAVOLAINEN, 2007). Esse novo conceito refere-se aos estudos que problematizam os:

[...] aspectos informacionais socioculturais (formas coletivas de se relacionar com a informação, critérios coletivos de relevância, necessidade, etc.) e os comportamentos informacionais individuais. (ARAÚJO, 2013, p. 21).

O termo práticas informacionais, segundo Savolainen (2007), aparece, fugazmente, na literatura da área nas décadas de 1960 e 1970, mas uma discussão mais substancial ocorre apenas na década de 2000. No campo de usuários da informação, esse conceito vem sendo apropriado pelos pesquisadores para se investigar os modos como os sujeitos lidam com a informação. Savolainen (2007) identifica, na sociologia e na antropologia, as raízes teóricas do conceito. Já Araújo (2013) vê o conceito de práticas informacionais advindo da noção de 'práticas', da Etnometodologia, cuja origem se dá, em meados do século XX, “como alternativa teórica ao Funcionalismo", desenvolvendo "uma série de conceitos que também enfatizam o papel ativo dos sujeitos sobre as determinações que sobre eles incidem" (ARAÚJO, 2013, online). Segundo o autor, essa perspectiva enfatiza a dimensão dos significados que as pessoas atribuem a tudo o que as rodeiam, inclusive suas próprias ações.

Essa é uma característica essencial da abordagem social: não se busca um método explicativo para os fenômenos informacionais, como nas abordagens anteriores, mas sim a compreensão de tais fenômenos. As práticas informacionais, portanto, pertenceriam ao que a Araújo (2012) denominou de abordagem interacionista dos estudos de usuários, uma vez que interação se mostra como conceito capaz de integrar os avanços do campo.

Interação significa "ação recíproca". O conceito põe em relevo o fato de uma ação ou influência exercida por algo pode ser também afetada por esse algo. Pensando nas questões em discussão aqui, teríamos que, numa perspectiva interacionista, o usuário não é totalmente determinado pelo contexto no insere, nem é totalmente 
isolado ou alheio a ele; a determinação que o contexto exerce, é real, mas não é mecânica nem absoluta, é interpretada e alterada pelo sujeito (ARAÚJO, 2012, p. 149).

Assumindo essa noção de interação, destacamos um primeiro elemento para o entendimento das práticas informacionais: a dimensão da coletividade. Nós não estamos sozinhos no mundo e, portanto, toda e qualquer relação que estabelecemos é mediada por outras pessoas. Desde o momento em que nascemos incorporamos referenciais sociais, construídos coletivamente e que nos são dados. Esses referenciais podem ser modificados ao longo do tempo e cada pessoa é, ao mesmo tempo, influenciada por eles e os influencia, também. É um processo dialético entre os referenciais sociais e a subjetividade de cada sujeito. Ao mesmo tempo, há uma dimensão de singularidade nessa abordagem, porque não se buscam generalizações, uma vez que os fenômenos informacionais são investigados a partir do contexto específico, temporal e situacional no qual eles ocorrem.

Uma reconstrução significativa dessa abordagem é a noção de informação, que deixa de ser considerada como algo que depende apenas da cognição de um indivíduo (sujeito antes estudado fora de seu contexto sociocultural) e passa a ser vista como um produto da intersubjetividade presente na sociedade. A informação é entendida como um processo cujo significado engloba várias dimensões, desde a manifestação física ou material de um determinado registro (seja uma obra, um objeto de museu, um livro ou um documento digital, entre outros.); até as ações humanas de interpretação e apropriação da realidade e de seus objetos. E ainda, as ações envolvidas nos procedimentos técnicos (como os que ocorrem em museus, bibliotecas, arquivos e sistemas de informação) e as mais variadas apropriações que os sujeitos fazem da informação, em diferentes contextos (ARAÚJO, 2013). Assim, entende-se que a informação não é neutra, pois é constituída dentro de uma dimensão sociocultural.

Tem-se uma nova forma de enxergar a informação e a maneira como os sujeitos conhecem e apreendem a realidade: a informação não é vista como redutora de incertezas ou algo que preenche vazios na mente, mas ao contrário, 
ela deve ser capaz de provocar mais dúvidas e inquietações no sujeito; e o conhecimento é percebido como resultado da interação do sujeito com a realidade, a partir de seus próprios critérios de valor e de relevância, por exemplo.

Supera-se, portanto, a noção de conhecimento como algo totalmente objetivo, como assumido na abordagem tradicional e, também, a noção de conhecimento como um processo de acumulação, da abordagem cognitiva. No estudo das práticas informacionais, assume-se que o sujeito relaciona-se com a realidade de variadas maneiras, não apenas pela mente, mas também pelos seus sentimentos e interesses, dentre outros. O conhecimento é, então, entendido como um processo dialético de assimilação e de acomodação. É um processo permanente de construção mútua de significados.

Cada sujeito já possui uma estrutura prévia de conhecimentos e quando ele recebe um novo estímulo ou dado conceitual, ocorrem os processos de assimilação e acomodação. A assimilação é o processo pelo qual o sujeito percebe o ambiente e o organiza, ampliando as suas estruturas prévias. A acomodação pode-se dar por meio da criação de um novo esquema ou a modificação de um esquema já existente, para que o novo estímulo possa ser incluído (PIAGET, 1996). Cada sujeito apresenta uma estrutura prévia diferente para entender a realidade, e a própria realidade apresenta elementos que modificam a estrutura prévia do sujeito. É um processo dialético, que ocorre de modo distinto para cada sujeito, visto que somos formados por diferentes experiências e interesses.

Essa noção de conhecimento aproxima-se da concepção defendida por Freire (2007). O autor critica a 'concepção bancária da educação', na qual a aprendizagem e conhecimento são processos de repetição e memorização, sem apreensão do real significado do conteúdo que é 'depositado’ ou arquivado fora da práxis. Ele defende uma concepção de educação problematizadora ou libertadora, de caráter essencialmente reflexivo, na qual só existe o saber, e o conhecimento, quando há criatividade, transformação. "Só existe saber na invenção, na reinvenção, na busca inquieta, impaciente, permanente, que os homens fazem no mundo, com o mundo e com os outros." (FREIRE, 2007, p. 
67). Assim, um sujeito não cria saberes sozinho, isolado, uma vez que o conhecimento só se dá coletivamente, na interação dos sujeitos com o mundo que os cerca.

A partir de pressupostos e concepções assumidos pela abordagem sociocultural, percebemos que alguns elementos - antes deixados de lado nas investigações sobre a interação dos sujeitos com a informação - são retomados na tentativa de se compreender os fenômenos informacionais em sua real complexidade. Araújo (2015) aponta dois conceitos que podem contribuir para a consolidação de uma base conceitual para as práticas informacionais: a imaginação e a sociabilidade.

A imaginação foi, durante muito tempo, mal vista pela Ciência. Contudo, ela vem sendo retomada recentemente e percebida como uma característica inerente do ser humano, uma potência. É nessa direção que Araújo (2015) propõe a apropriação da noção de imaginação simbólica, de Gilbert Durand, em uma tentativa de superar o caráter restritivo das abordagens anteriores.

A imaginação simbólica é a capacidade do ser humano de criar, representar e simbolizar. Nós apreendemos o mundo de duas maneiras basicamente: de modo direto, através dos nossos cinco sentidos; e de modo indireto, na ausência do objeto, pela dimensão simbólica, representando e atribuindo significados para todos objetos do mundo. Mesmo no modo direto, através dos sentidos, o sujeito apreende o mundo atribuindo significado às coisas, pois esta é uma característica intrínseca do sujeito: ele não consegue conhecer a realidade sem representar, classificar e atribuir significados aos objetos do mundo (DURAND, 1993). Daí que vem a noção de pregnância simbólica, um processo contínuo de construção de significado que o ser humano faz em relação a tudo com o que interage.

O campo da imaginação simbólica estaria, então, nas formas de apreensão indireta da realidade, quando fazemos representações que remetem a determinados objetos. E é essa ação de representar que possibilita "[...] abrir as portas para o novo e, ao fazer isso, estende a realidade." (ARAÚJO, 2015, doc. não paginado). Durand (1993, 1997) destaca duas ideias neste sentido: (1) a capacidade de imaginação está em todo pensamento do ser humano; (2) a 
dimensão simbólica está relacionada com a capacidade de reflexão dos homens. Desse modo, evidencia-se uma das quatro funções da imaginação simbólica, segundo o autor: a função teofânica, que refere-se exatamente a esse processo interminável de criação de sentido que sempre resulta em algo novo. Por isso mesmo, a nossa relação com a realidade nunca é completa e absoluta, mas está sempre em construção. Desta forma, a noção de conhecimento, adotada nesta abordagem, está, intrinsecamente, ligada a esta dimensão da imaginação simbólica, sendo esse último um elemento inerente ao ato de criação e de construção do conhecimento.

Já o conceito de sociabilidade surge na tentativa de superar o caráter isolacionista dos usuários nas abordagens anteriores. Nós vivemos no mundo com os outros e agimos em função dos outros também, seja com um objetivo ou um interesse que orienta a ação; ou pelo simples desejo de estar com outros em uma relação. A sociabilidade "[...] é uma dessas inúmeras formas através das quais os indivíduos se associam, mas - e diferentemente das outras - marcada pela inexistência de fins práticos.” (FRANÇA, 1995, p. 60). É quando a relação acontece por si mesma, quando "Os indivíduos se comprazem em estabelecer laços, e esses laços têm em si mesmos sua razão de ser." (FRANÇA, 1995, p. 60). Na dimensão informacional, isto significa pensar que as práticas informacionais têm seu lugar também, em meio a outras práticas cotidianas dos sujeitos, isto é, no campo da sociabilidade.

Diante da tentativa de caracterizar o conceito de práticas informacionais, explicitando seus elementos e dimensões, ressaltamos seu caráter complexo, um traço particular dos objetos e aportes teóricos e metodológicos das Ciências Sociais e Humanas, visto que nosso objeto de estudo é o homem, ser cognoscente, dotado de interesses e vontades, além da sua historicidade. Tal objeto de estudo, tão complexo, requer uma teoria igualmente complexa, de modo a lidar com as categorias mais singulares e transitórias que se apresentam.

As nossas ações relacionadas à informação vão muito além das investigações sobre quais fontes e canais de informação são utilizados pelos usuários. O conceito de práticas informacionais busca compreender a relação de cada ação do sujeito com a cultura, com os referenciais sociais que nos cercam e 
nos influenciam; busca também compreender qual o significado as ações têm para o próprio sujeito que as realiza, pois as ações praticadas diariamente (e as práticas informacionais realizadas no cotidiano) ganham valor a partir do momento em que os sujeitos as apreendem e dão significado a elas.

Como destaca Nunes (2014), a perspectiva das práticas informacionais confere ao sujeito o papel de protagonista, pois parte-se da ideia de que cada sujeito interage com a informação de modo distinto, cada um tem seu próprio entendimento sobre o que é ou não informação, sobre o que é ou não relevante pra si mesmo, sobre o que eles querem ou não se apropriar.

Diante do exposto, esboçamos uma noção de práticas informacionais como um fazer etnográfico. Refere-se ao modo como as pessoas dão significado às suas próprias ações, no que tange a interação com a informação nos mais diversos contextos.

Angrosino (2009) define a etnografia como "A arte e a ciência de descrever um grupo humano - suas instituições, seus comportamentos interpessoais, suas produções materiais e suas crenças." (ANGROSINO, 2009, p. 30). É fundamental a inserção do pesquisador no grupo ou na comunidade que se pretende estudar, com a observação participante, pois somente partilhando as experiências vivenciadas no cotidiano do grupo, ele poderá compreendê-lo.

Os estudos sobre cultura, segundo Geertz (2014), não podem ser realizados como uma ciência experimental em busca de leis, mas sim como uma ciência interpretativa, em busca de significado. $\mathrm{O}$ autor acredita que o homem é “[...] um animal amarrado a teias de significados que ele mesmo teceu, assumindo a cultura como sendo essas teias e a sua análise." (GEERTZ, 2014, p. 4). Assim, a etnografia é muito mais do que uma questão de métodos. Técnicas e processos podem integrar a etnografia, mas o que a define é "o tipo de esforço intelectual que ele representa: um risco elaborado para uma descrição densa" (GEERTZ, 2014, p. 4). O pesquisador deve, por meio da etnografia, ser capaz de compreender o real significado por trás das ações dos sujeitos. Deve-se interpretar as ações dos sujeitos, buscando entender como e por que (situado temporal e contextualmente) aquilo aconteceu. 
Malinowski sugere três questões que o pesquisador deve levar a campo, de modo a orientar todo o seu trabalho: (1) o que os nativos dizem sobre o que fazem; (2) o que realmente fazem; (3) o que pensam a respeito do que fazem (GOLDENBERG, 1998). Com estas questões sempre em mente, o pesquisador deve realizar a sua descrição densa, não se prendendo às aparências iniciais e descrições superficiais sobre o fenômeno investigado.

Vislumbramos diversas contribuições do conceito de práticas informacionais para os estudos de visitante de museus. Primeiramente, salientamos a evolução do campo de estudos de visitante, especialmente devido às abordagens e os modelos recentes, que são orientados por perspectivas socioculturais ou sociocognitivas. Estes modelos assumem alguns pressupostos em comum com as práticas informacionais. O modelo de Falk e Dierking (2011), por exemplo, entende que os visitantes não chegam 'vazios' ao museu, uma vez que eles possuem uma série de bagagens, experiências e conhecimentos prévios que eles levam em sua interação com os elementos do museu. Os autores assumem também, que cada sujeito se apropria de modo distinto das informações, e que o processo de criação de sentido e construção do conhecimento é diferente para cada um, o que torna única cada experiência de visita. Além disso, há a compreensão de que tanto a visita quanto a construção de conhecimento não se iniciam apenas quando o sujeito chega ao museu e nem termina quando ele sai: é um processo que se inicia muito antes e que pode durar dias, semanas, meses ou até mais tempo.

Tais conjecturas e essa noção de conhecimento aproximam-se dos pressupostos das práticas informacionais. Contudo, entendemos que tal conceito pode contribuir ainda mais para com os estudos de visitante, uma vez que considera outros tantos elementos (discutidos anteriormente) como constituintes da experiência de visita ao museu e da interação dos sujeitos com a informação, que podem favorecer uma compreensão mais efetiva do objeto investigado.

Uma primeira contribuição seria a apropriação do conceito de práticas informacionais enquanto um fazer etnográfico, que investiga os significados que os sujeitos conferem às suas próprias ações. Para se compreender a experiência de visita é essencial ir além de uma observação superficial de comportamentos 
externamente observáveis. A observação participante, como prevista na etnografia, permite que pesquisador compreenda as dinâmicas que se efetivam no espaço do museu, em uma descrição 'densa' do fenômeno. Aliada à técnica de entrevista semiestruturada, a investigação não se limita a descobrir o que os visitantes dizem que fazem no museu, mas torna-se possível compreender como os sujeitos realmente interagem com os elementos do museu e o que tais ações significam para eles mesmos.

Outra contribuição é o seu olhar característico. Os estudos das práticas informacionais consideram a interação dos sujeitos com a informação, bem como a experiência de visita, fenômenos complexos, dialéticos, nos quais um indivíduo ou uma instituição não podem ser estudados de modo isolado, com foco em apenas uma dimensão - como a educacional ou a cognitiva -, desconsiderando uma gama de contextos históricos, políticos e socioculturais nos quais eles estão inscritos. Tais dimensões já começaram a ser abordadas nos estudos da abordagem cognitiva e nos modelos mais recentes dos estudos de visitante, mas muitas vezes são percebidas apenas como fatores que interferem nas ações dos sujeitos e não fatores que efetivamente constituem suas as ações e opiniões, como defende o conceito de práticas informacionais.

A principal contribuição se dá na grande importância atribuída à dimensão simbólica, que permeia todas as demais e é vista como uma potência do ser humano - elemento essencial na interação do sujeito com a realidade social e na construção do conhecimento. Como dito anteriormente, o sujeito relaciona-se com os objetos da realidade pelos seus cinco sentidos e de modo indireto, pela imaginação simbólica. Em sua experiência de visita, o sujeito interage com objetos e artefatos, com conteúdos disponibilizados em diferentes suportes e com outras pessoas, visitantes ou funcionários do museu. Nossa apreensão da realidade passa pela linguagem e decodificação de códigos e pela negociação de significados, exigindo mais do que apenas nossas capacidades intelectuais. Como afirma Rendón Rojas (2005), é necessário empregar a fantasia, a imaginação e a criatividade. E a dimensão simbólica que permite ao ser humano a inovação, a criação e a diversidade cultural. 


\section{Aportes metodológicos}

A pesquisa realizada é de caráter essencialmente qualitativo, embasando-se no conceito de práticas informacionais enquanto um fazer etnográfico. $\mathrm{O}$ objetivo não é investigar o nível de satisfação dos sujeitos com a exposição ou avaliar qual o entendimento ou o nível de aprendizagem deles após a visita. Contudo, busca-se compreender como o sujeito interage com a informação e os objetos do museu em sua experiência de visita, considerando o contexto sociocultural que envolve tanto o visitante quanto o próprio museu.

$\mathrm{O}$ intuito de se investigar o fenômeno escolhido utilizando-se a etnografia se deu a partir da percepção de que ela pode nos levar à compreensão das especificidades da experiência de visita, das singularidades da relação entre os sujeitos, a informação e os contextos e referenciais sociais que os cercam. A etnografia permite que o pesquisador entre em contato com o universo estudado, compartilhando o horizonte dos nativos, mas não no intuito de:

Atestar a lógica de sua visão de mundo, mas para, seguindoos até onde seja possível, numa verdadeira relação de troca, comparar suas próprias teorias com as deles e assim tentar sair com um modelo novo de entendimento. (MAGNANI, 2009, p. 135).

Recorremos às técnicas de observação participante e entrevista semiestruturada para a coleta de dados. A observação pode ser entendida como "O ato de perceber um fenômeno, muitas vezes com instrumentos e registrá-los com propósitos científicos." (ANGROSINO, 2009). Interagindo com os sujeitos da pesquisa e com todo o ambiente, a observação possibilita a realização de uma descrição densa do fenômeno. Assim, o pesquisador pode compreender as singularidades do fenômeno e das relações ali estabelecidas.

A coleta de dados complementa-se com as entrevistas semiestruturados, nas quais o pesquisador elabora um roteiro com tópicos a serem explorados e pode, no decorrer de cada entrevista, acrescentar ou alterar algum tópico ou pergunta. Aliando as duas técnicas, acreditamos coletar dados que nos permitam alcançar a dimensão simbólica a fim de compreender os significados que os sujeitos conferem às suas ações, no que tange à interação com a informação durante a experiência de visita ao Museu Itinerante Ponto UFMG. 


\subsection{O objeto empírico}

O Museu Itinerante Ponto UFMG nasceu em 2006, concebido como projeto de extensão da Universidade Federal de Minas Gerais (UFMG), no intuito de promover ações que visam aproximar o conhecimento científico produzido e a sociedade. É um espaço dedicado, principalmente, a alunos e professores da Educação Básica, visando desenvolver ações de formação de professores num “[...] espaço de aprendizagem e a promoção de estímulos a favor do conhecimento, do método e da opinião científica, em que a ciência seja trabalhada como processo em construção, despertando vocações científicas." (COSTA, 2014, p. 7).

O Museu Itinerante Ponto UFMG é composto por um caminhão, adaptado em seis salas temáticas, e uma exposição externa. O museu leva suas exposições a inúmeras cidades de Minas Gerais e de todo o Brasil; além de participar de eventos científicos, como as reuniões da Sociedade Brasileira para o Progresso da Ciência (SPBC). As salas do caminhão abordam a relação entre o homem, a tecnologia e a natureza. Costa (2014) caracteriza cada uma das salas da exposição do caminhão:

a) a sala do Útero consiste na simulação do ambiente intrauterino, remetendo os visitantes a sensações vividas durante a permanência na barriga materna. O intuito é a reflexão sobre si mesmo, sua origem e seu futuro como ser humano;

b) na sala dos Sentidos, o visitante descobre várias formas de perceber o mundo através dos sentidos (paladar, audição, olfato, tato e visão), interagindo com modelos de representação dos órgãos responsáveis por cada sentido, numa sala revestida por ilusões de ótica.

c) a sala dos Biomas é constituída por ambientes que buscam mostrar o contato do homem com três diferentes tipos de biomas ( o Cerrado, a Floresta Tropical e a Antártica), cuja temperatura, fauna e flora variam drasticamente. Essa experiência visa contribuir com a percepção de que uma mudança de atitude diante da natureza que nos rodeia pode melhorar a condição do ser humano no planeta. 
d) a sala de Projeção exibe um vídeo didático em 3D que mostra uma fascinante viagem por diversos ambientes do planeta, para que sejam compreendidos aspectos de sua grandeza e diversidade.

e) a sala do Submarino simula o ambiente da cabine de controle de um submarino submerso em águas profundas. Ao entrar, os visitantes veem os seres abissais através de escotilhas, orientando-se pelo sonar e simulando a visão do ambiente pelo uso do periscópio.

f) a sala das Cidades permite ao visitante fazer uma visita a várias cidades do mundo, através de um recurso de telas. É possível, assim, constatar que a tecnologia pode nos levar a lugares para onde nunca fomos.

A exposição externa é um espaço constituído de três principais temáticas: O Espaço do Corpo Humano, que expõe modelos relativos ao corpo humano e ao corpo de animais; o Espaço Energia expõe diversos experimentos de física, simulando como se dá a produção de diferentes tipos de transformações energéticas; e o Espaço Desafio propõe uma série de jogos e desafios das diferentes áreas do conhecimento aos visitantes (COSTA, 2014).

\subsection{Universo e amostra}

O universo de pesquisa é constituído por pessoas que visitaram o Museu Itinerante Ponto UFMG durante a $67^{\mathrm{a}}$ Reunião Anual da SBPC, no período entre 12 a 18 de julho de 2015, realizada em São Carlos, SP.

As reuniões anuais da SBPC são constituídas por uma ampla gama de atividades. A programação científica é composta por conferências, simpósios, mesas-redondas, encontros, sessões especiais, minicursos, sessões de pôsteres e exposições (SBPC, 2015). Em 2015, o Ponto UFMG foi alocado como uma atividade da SBPC Jovem, no campus da Universidade Federal de São Carlos (UFSCar). Embora tenha, a principio, programação voltada para alunos do ensino básico, a SBPC Jovem e o Ponto UFMG receberam um público diverso, com pessoas de idades e escolaridade variadas.

A pesquisadora viajou para a cidade de São Carlos junto com a equipe do Museu Itinerante Ponto UFMG, auxiliou na montagem e desmontagem da 
exposição, o que proporcionou maior interação com os elementos do museu e maior conhecimento sobre os mesmos. Ao interagir os visitantes para realizar as entrevistas, a pesquisadora identificava-se como tal e esclarecia que a entrevista seria realizada como parte de uma tese de doutorado. A observação participante foi realizada durante todos os dias do evento, com registros escritos e gravados em áudio. Durante o mesmo período, foram realizadas entrevistas semiestruturadas gravadas com 143 visitantes. Para a realização das entrevistas, foi elaborado um roteiro com três grandes tópicos: (1) as especificidades da experiência de visita; (2) a relação com museus de modo geral; (3) as questões de identificação e hábitos cotidianos. Os entrevistados foram escolhidos aleatoriamente, de acordo com a disponibilidade deles.

A análise de dados se deu a partir da leitura e releitura dos áudios das observações e das entrevistas, bem como da leitura das transcrições delas. Dessa forma, buscou-se descrever a experiência de visita ao museu dos sujeitos, qualificando variáveis que destacaram-se nos depoimentos e observações.

\section{Especificidades da experiência de visita ao Museu itinerante Ponto UFMG}

Embasadas pelos aportes teóricos e metodológicos explanados anteriormente, apresentamos algumas impressões iniciais da análise dos dados.

Embora o público alvo do Museu Itinerante Ponto UFMG seja, principalmente, alunos e professores da educação, verificou-se um perfil diferenciado durante os dias de exposição na SPBC, em São Carlos. Durante todos os dias de exposição, o museu foi visitado por pessoas de diferentes idades e nacionalidades. Os participantes eram estudantes de graduação e pós-graduação, professores e/ou pesquisadores de universidades, turmas e professores de alunos da educação básica e a sociedade em geral.

Analisando os dados obtidos com a observação e as entrevistas, foi evidenciado que, embora a maior parte dos visitantes do museu esteve presente no local devido à participação na SBPC, as duas exposições do museu - a do caminhão e a exposição externa - chamaram muito a atenção das pessoas que passaram por perto. A todo instante era possível ouvir as pessoas comentando 
entre si ou perguntando para os mediadores que permanecem do lado de fora do caminhão: "O que tem aí dentro do vidro preto?" ou "O que tem nesse caminhão?”.

Compreendemos que são inúmeros os fatores que influenciam o modo como o sujeito interage com os elementos do museu e o percurso realizado. Tais fatores puderam ser observados, principalmente, na exposição externa, uma vez que a exposição do caminhão é guiada e segue sempre a mesma ordem no percurso das salas.

Além disso, percebemos que, muitas vezes, as falas dos entrevistados sobre suas ações contradizem as observações da pesquisadora sobre determinados aspectos da visita. Eles afirmam ter feito um percurso e interagido de determinada forma com os elementos da exposição, mas agiram de outra forma. A explicação para tal postura está num misto de fatores que perpassa pela concepção que o sujeito tem sobre museus de uma forma geral e pelo nível de preocupação que cada visitante tem a respeito da imagem que eles querem transmitir de si mesmos para os demais, dentre outros.

Exploramos aqui um momento da experiência de visita em que essa situação ocorreu. Ao serem observados durante todo o tempo em que permaneceram no museu, os visitantes foram entrevistados após terminarem a visita. O roteiro de entrevistas incluiu questões sobre as especificidades da experiência de visita, e os sujeitos foram questionados sobre o percurso que escolheram fazer, sobre os objetos, experimentos e/ou desafios com os quais interagiram, assim como sobre a interação com as informações na exposição.

$\mathrm{Na}$ ocasião em que foram questionados pela primeira vez sobre o percurso e o nível de interação com cada item da exposição, muitos visitantes declararam ter observado e interagido com todos os objetos, desafios e experimentos de cada uma das três galerias da exposição externa e afirmam ter lido todas as placas explicativas de todos itens visitados. Todavia, durante a observação, em muitos casos, foi constatado que esse não foi o percurso real do visitante e que ele não leu as placas, como havia afirmado.

Quando questionados uma segunda ou terceira vez (a pesquisadora refez algumas questões várias vezes, em diferentes momentos da entrevista, no intuito 
de captar contradições na fala do entrevistado e extrair dados para justificar o comportamento observado dos sujeitos) ou quando solicitados a relembrar como interagiram com cada item, muitos visitantes assumem que, na verdade, eles não interagiram com todos os objetos e não leram as placas, como haviam alegado anteriormente. Observa-se que alguns visitantes não se preocupam em explicar a contradição entre a fala inicial e as práticas observadas, eles apenas desconversam e afirmam terem interagido apenas com os objetos que mais chamaram sua atenção e olhado, brevemente, algumas placas explicativas. Outros visitantes, em contrapartida, continuam insistindo que visitaram cada um dos objetos da exposição, leram as plaquinhas e não são capazes de falar sobre um determinado objeto - quando questionados pela entrevistadora - porque já esqueceram o que leram e como interagiram com tal objeto.

A explicação para tal conduta está em uma série de fatores. Muitos entrevistados compartilham da visão de que visitar um museu e não interagir com todos os itens lá expostos e, principalmente, não ler as placas explicativas é algo malvisto na sociedade. Essa noção advém da visão que esses entrevistados têm sobre museus de forma geral, a qual eles acreditam ser compartilhada pela sociedade. Para estes sujeitos, o museu é visto como um local de aprendizado e de aquisição de conhecimentos e cultura. Assumindo essa concepção sobre museus, a primeira reação dos entrevistados, ao serem questionados sobre a visita, é afirmar que visitaram todos os itens expostos, interagiram com todos, leram todas as placas e adquiriram novos conhecimentos durante a experiência de visita. Eles querem ser vistos como pessoas cultas, que frequentam museus do modo 'correto', e não como alguém que não faz aquilo que seria esperado no ambiente do museu.

Segundo Goffman (2013), nós agimos de certa forma na realidade social, em função daquilo que queremos 'transmitir' sobre nós para os outros e esperamos que outros reajam de determinada forma às nossas ações.

Assim, quando uma pessoa chega à presença de outras, existe, em geral, alguma razão que a leva a atuar de forma a transmitir a elas a impressão que lhe interessa transmitir. (GOFFMAN, 2013, p. 16). 
No caso dos entrevistados (que não sabiam previamente que estavam sendo observados durante a visita à exposição externa), ao falar sobre a sua experiência de visita e o modo como interagiram com os elementos do museu, eles responderam aquilo que levaria o entrevistador - e os demais atores presentes - a pensar o que eles gostariam que os outros pensassem sobre eles. Se para eles, a visão da sociedade sobre museu é de que esse é um lugar de adquirir cultura e conhecimento (como ficou evidenciado em outros momentos das entrevistas), um local frequentado por pessoas consideradas 'cultas' e 'inteligentes', essa também é a imagem de si mesmos que eles querem transmitir aos outros. Estes entrevistados são, em maioria, professores de universidades federais de diversas regiões do país e estudantes de graduação e pós-graduação, que possuem nível de instrução mais elevado e se sentiram constrangidos em dizer que as suas próprias ações durante visita não correspondem ao que seria esperado deles, pelos papeis que exercem e pela visão sobre a instituição museu que eles acreditam compartilhar com a sociedade.

\section{Considerações finais}

O conceito de práticas informacionais adotado mostra-se adequado, conforme os resultados já alcançados na análise, para o desvelamento da experiência de visita a museus, entendendo-o como fenômeno complexo, que vai além de indicadores quantitativos de satisfação ou níveis de aprendizagem alcançada. Adotando uma postura compreensiva, a investigação sobre a experiência de visita revela categorias passíveis de serem qualificadas e não quantificadas.

A observação participante, aliada à técnica de entrevista semiestruturada, mostrou-se adequada aos objetivos da pesquisa e apropriada para desvelar os significados da experiência de visita ao museu. A articulação dessas técnicas de coleta de dados nos possibilitou não apenas captar o que os visitantes dizem que fazem, mas também o que eles realmente fazem e o que pensam a respeito do que fazem, como destacado por Malinowski. Evidenciou-se, em vários momentos, que os sujeitos, muitas vezes, agem de uma forma e afirmam ter agido de outra, por diversas razões, como no exemplo dado na seção anterior. 
Como sugestões para pesquisas posteriores, propomos a realização de investigações de práticas informacionais em museus que comparem experiências de visita em diferentes tipos de museus, como museus artísticos, históricos e etnográficos, dentre outros.

\section{Referências}

ALONSO FERNÁNDEZ, L. Nueva museología: planteamientos y retos para El futuro. Madrid: Alianza, 2012.

ANGROSINO, M. Etnografia e observação participante. Porto Alegre: Artmed, 2009.

ARAÚJO, C. A. A. Estudos de usuários conforme o paradigma social da ciência da informação: desafios teóricos e práticos de pesquisa. Informação \& Informação, Londrina, v. 15, n. 2, p. 23-39, jul./dez. 2010. Disponível em: <http://www.uel.br/revistas/uel/index.php/informacao/article/view/6485/6995>. Acesso em: 26 jun. 2016.

ARAÚJO, C. A. A. Paradigma social nos estudos de usuários da informação: abordagem interacionista. Informação \& Sociedade: Estudos, João Pessoa, v. 22, n.1, p. 145-159, jan./abr. 2012. Disponível em:

<http://www.ies.ufpb.br/ojs/index.php/ies/article/view/9896>. Acesso em: 26 jun. 2016.

ARAÚJO, C. A. A. Museologia e Ciência da Informação: diálogos possíveis. Revista Museologia \& Interdisciplinaridade, Brasília, v. 2, n. 4, p. 10-27, maio/jun. 2013. Disponível em:

<http://periodicos.unb.br/index.php/museologia/article/view/9624/7103>.

Acesso em: 26 jun. 2016.

ARAÚJO, C. A. A. Imaginação e sociabilidade: novos conceitos para o estudo de usuários da informação. In: ENCONTRO NACIONAL DE PESQUISA EM CIÊNCIA DA INFORMAÇÃO, 16., 2015, João Pessoa. Anais... João Pessoa: UFPB, 2015. Disponível em:

<http://www.ufpb.br/evento/lti/ocs/index.php/enancib2015/enancib2015/paper/v iew/2981/1045>. Acesso em: 10 fev. 2016.

CHOO, C. W. A organização do conhecimento: como as organizações usam a informação para criar significado, construir conhecimento e tomar decisões. São Paulo: Senac, 2003.

COSTA, T. M. L. Portfólio Museu Itinerante Ponto UFMG. Belo Horizonte: Universidade Federal de Minas Gerais, 2014. 
DURAND, G. A imaginação simbólica. Lisboa: Edições 70, 1993.

DURAND, G. As estruturas antropológicas do imaginário. Lisboa: Presença, 1997.

FALK, J. H.; DIERKING, L. D. The museum experience. 2. ed. Left Coast Press: Walnu Creek, CA, 2011.

FRANÇA, V. R. V. Sociabilidade: implicações do conceito no estudo da comunicação. In: FAUSTO NETO, A.; PORTO, S.; BRAGA, J. L. (Org.). A encenação dos sentidos: mídia, cultura e política. Rio de Janeiro: Diadorim, 1995. p. 55-66.

FREIRE, P. Pedagogia do oprimido. 45. ed. Rio de Janeiro: Paz e Terra, 2007. $213 \mathrm{p}$.

GEERTZ, C. A interpretação das culturas. Rio de Janeiro: LTC, 2014.

GOFFMAN, E. A representação do eu na vida cotidiana. 19. ed. Petrópolis, RJ: Vozes, 2013.

GOLDENBERG, M. A arte de pesquisar: como fazer pesquisa qualitativa em Ciências Sociais. 2. ed. Rio de Janeiro: Ed. Record, 1998.

GONZÁLEZ TERUEL, A. Los estudios de necesidades y usos de la información: fundamentos y perspectivas actuales. Gijón: Trea, 2005.

FIGUEIREDO, N. M. Estudos de usuários. In: FIGUEIREDO, N. M. Estudos de usos e usuários da informação. Brasília: IBICT, 1994. p. 7- 86. Disponível em: 〈http://livroaberto.ibict.br/handle/1/452〉. Acesso em: 26 jun. 2016.

HOOPER-GREENHILL, E. Los museos y sus visitantes. Gijón: Trea, 1998.

KÖPTCKE, L. S. Observar a experiência museal: uma prática dialógica? In: FUNDAÇÃO OSWALDO CRUZ. Casa de Oswaldo Cruz. Museu da Vida. Avaliação e estudos de público de museus e centros de ciência. Rio de Janeiro: a Fundação, 2003. p.5-21. (Cadernos do Museu da Vida, 2). Disponível em: <http://www.museudavida.fiocruz.br/media/Cadernos-do-Museu-da-Vida2003.pdf>. Acesso em: 26 jun. 2016.

MAGNANI, J. G. C. Etnografia como prática e experiência. Horizontes Antropológicos, Porto Alegre, ano 15, n. 32, p. 129-156, jul./dez. 2009. Disponível em: 〈http://www.scielo.br/pdf/ha/v15n32/v15n32a06.pdf >. Acesso em: 26 jun. 2016.

NUNES, J. V. Vivência em rede: uma etnografia das práticas sociais de informação dos usuários de redes sociais na internet. 2014. 307f. Tese 
(Doutorado em Ciência da Informação). Programa de Pós-graduação em Ciência da Informação, Universidade Estadual Paulista, Marília, SP, 2014. Disponível em:

<http://repositorio.unesp.br/bitstream/handle/11449/110781/000798943.pdf?seq uence $=1 \&$ is Allowed $=y>$. Acesso em: 26 jun. 2016.

PÉREZ SANTOS, E. Estudio de visitantes en museos: metodología y aplicaciones. Gijón: Trea, 2000.

PIAGET, J. Biologia e conhecimento. 2. ed. Petrópolis, RJ: Vozes, 1996.

RENDÓN ROJAS, M. A. Relación entre los conceptos: información, conocimiento y valor. Semejanzas y diferencias. Ciência da Informação, Brasília, v. 34, n. 2, p. 52-61, maio/ago. 2005. Disponível em:

<http://revista.ibict.br/ciinf/article/view/1090/1198>. Acesso em: 26 jun. 2016.

SAVOLAINEN, R. Information behavior and information practice: reviewing the "umbrella concepts" of information-seeking studies. The Library

Quarterly, Chicago, v. 77, n. 2, p. 109-132, 2007.

SBPC. REUNIÃO ANUAL DA SOCIEDADE BRASILEIRA PARA O PROGRESSO DA CIÊNCIA, 67., 2015, São Carlos, SP. Disponível em: <http://www.sbpcnet.org.br/saocarlos/sobre/>. Acesso em: 23 nov. 2015.

WILSON, T. D. On user studies and information needs. Journal of Documentation, Bingley, v. 37, n. 1, p. 3-15, 1981.

\title{
Information practices of the Ponto UFMG Itinerant Museum's
} visitors

\begin{abstract}
This study explores a point of dialogue between the information users studies and Museology's visitors studies and it investigates the interaction of Ponto UFMG Itinerant Museum's visitors with information. The research is based on the concept of information practices as an ethnographic doing, using observation and interview for data collection. The results show that many factors influence the interaction between the visitor and the museum elements. Often, the respondents' reports contradict the observations, and the explanation for that is a combination of factors, including the conception about museums that the visitors have and the level of concern they have about the image they want to transmit about themselves. We conclude that the participant observation combined with the interview, proved to be appropriate in order to unveil the meanings of the visit experience, enabling us to capture not only what visitors
\end{abstract}


say they do, but also what they actually do and what they think about what they do.

Keywords: Information practices. Information Behavior. Visitor Studies. Museums. Ethnography.

Recebido: 26/04/2016

Aceito: 09/06/2016 